\title{
Multiple myeloma: optimal management and long-term disease control
}

This article was published in the following Dove Press journal:

Blood and Lymphatic Cancer:Targets and Therapy

6 November 2014

Number of times this article has been viewed

Priya Sriskandarajah

Faith E Davies

Divisions of Molecular Pathology, Cancer Therapeutics, and Clinical Studies, Institute of Cancer

Research, Sutton, UK
Correspondence: Priya Sriskandarajah Institute of Cancer Research, I5 Cotswold Road, Sutton, London, SM2 5NG, UK

Email priya.sriskandarajah@icr.ac.uk
Abstract: Multiple myeloma is an incurable hematological disease previously associated with poor prognosis and survival rates. However, following the advent of the so-called novel agents, the goal of therapy has now moved to long-term disease control and potential cure. However, despite these advances, myeloma displays considerable heterogeneity and, over time, control of disease can be lost. In order to counteract this, new strategies are incorporating risk stratification to provide more individualized therapy. Furthermore, there is now increasing focus on adapting therapy in elderly and frail patients to improve compliance and maximize treatment benefit.

Keywords: combination regimes, frailty index, risk stratification, myeloma

\section{Introduction}

Myeloma is often considered a disease of the elderly, with a median age at presentation of 70 years. Fewer than $35 \%$ of patients presenting with newly diagnosed disease are below the age of 65 years. ${ }^{1,2}$ As a result, the goal of treatment has always been aimed at disease control rather than cure. However, over the last two decades the introduction of high-dose therapy with autologous stem cell transplant (ASCT), particularly for younger patients, has resulted in a significant improvement in survival rates. Furthermore, within all patients, the introduction of the immunomodulatory drugs (IMiDs), (thalidomide, lenalidomide, and pomalidomide), as well as the proteasome inhibitors bortezomib and carfilzomib, has made a significant impact on response and survival rates, especially in the elderly population (ie, those above the age of 65 years). ${ }^{3}$

In the last decade itself, there have been an increasing number of clinical trials aiming to optimize patient management. These include studies looking at two-drug versus three-drug regimens, proteasome and IMiD combinations with steroids and other chemotherapy, and the role of continuous treatment for long-term disease control. ${ }^{2,3}$ Furthermore, there has been increasing interest in risk stratification using fluorescence in situ hybridization techniques to identify underlying cytogenetic markers with prognostic significance. Interestingly, it has been found that certain markers are associated with a better response to particular treatments than others, which raises the possibility of providing increasingly targeted therapy directed to individual patient abnormalities in the future. ${ }^{4}$ In addition, strategies to adapt therapy for the individual patient have also included specific dose reductions for frail and elderly patients so that they may tolerate treatment and benefit from new treatment advances. 
This review will summarize the recent advances in the management of both transplant-eligible (TE) and non-TE (NTE) patients. Furthermore, it will also cover the role of continuous therapy in long-term disease control and the challenges that the introduction of such an approach may pose.

\section{Risk stratification}

The choice of therapy depends on two main areas: 1) patientrelated (ie, age, presence of comorbidities, and patient fitness) and 2) disease-related factors. ${ }^{5}$ Patient-related factors will be covered in more detail later in the review. Disease-related factors include:

- International Staging System, which consists of $\beta 2$-microglobulin and albumin levels, representing tumor burden and stage.

- Presence of plasma cell leukemia, extramedullary disease, or plasmablastic morphology.

- Cytogenetic markers, which can characterize the molecular profile of the tumor.

A number of studies have now highlighted the impact of cytogenetic markers on patient survival. Within the Medical Research Council (MRC) Myeloma IX study, a comprehensive fluorescence in situ hybridization panel was performed on all newly diagnosed patients. Fluorescence in situ hybridization lesions, which were associated with adverse progression-free survival (PFS) and impaired median overall survival (OS), included $\mathrm{t}(4 ; 14), \mathrm{t}(14 ; 16)$, and $17 \mathrm{p} 13$ deletion (Table 1$){ }^{6}$

Interestingly, the effect of the number of lesions was additive - those patients who carried only one adverse lesion showed only a moderate impact on their survival rate. However, if patients carried a number of lesions (ie, more than two), this had a greater impact on survival length; the worst survival was seen in patients with three lesions (Figure 1). ${ }^{6}$

Table I Survival times associated with cytogenetic groups defined by FISH in the Medical Research Council Myeloma IX study

\begin{tabular}{lllll}
\hline FISH lesion & $\begin{array}{l}\text { PFS with } \\
\text { lesion } \\
\text { (months) }\end{array}$ & $\begin{array}{l}\text { PFS without } \\
\text { lesion } \\
\text { (months) }\end{array}$ & $\begin{array}{l}\text { OS with } \\
\text { lesion } \\
\text { (months) }\end{array}$ & $\begin{array}{l}\text { OS without } \\
\text { lesion } \\
\text { (months) }\end{array}$ \\
\hline Hyperdiploidy & 18.9 & 17.8 & 49.7 & 43.7 \\
$\mathrm{t}(4 ; 14)^{*}$ & 13.1 & 19.3 & 27.7 & 50.9 \\
$\mathrm{t}(1 \mathrm{I} ; 14)^{*}$ & 21.3 & 17.5 & 51.6 & 46.9 \\
$\mathrm{t}(14 ; 16)^{*}$ & 13.6 & 18.6 & 32.9 & 48.3 \\
+ I q** & 13.8 & 22.1 & 31.0 & 54.8 \\
I7p deletion**** 14.7 & 18.3 & 26.7 & 48.5 \\
\hline
\end{tabular}

Notes: Data from Boyd et al. ${ }^{6}$ *Represents translocation between the two chromosomes. **Represents gain of function mutation involving the $\mathrm{q}$ arm in chromosome I. ***Represents deletion of a gene affecting $\mathrm{p} 53$ function on the $\mathrm{p}$ arm in chromosome 17.

Abbreviations: Iq, chromosome I chain; FISH, fluorescence in situ hybridization; PFS, progression-free survival; OS, overall survival; $t$, translocation.

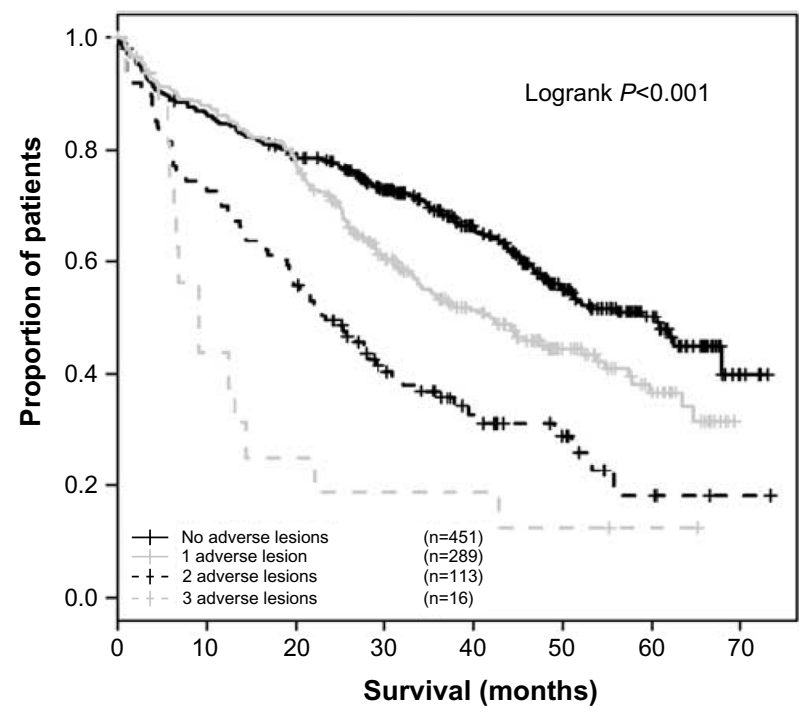

Figure I Overall survival graded by number of adverse lesions. Those with adverse IgH translocation, plus Iq, and I7p deleletion had the worst overall survival. Note: Data from Boyd et al. ${ }^{6}$

Abbreviations: IgH, immunoglobulin heavy chain; Iq, chromosome I chain.

Moreover, patients could be categorized into clinically relevant groups such as favorable versus high-risk disease according to their International Staging System score and the presence of adverse lesions. Those in the latter category had worse survival rates with a median OS of 19.4 months compared to 67.8 months (Table 2). ${ }^{6}$

More recently there has been suggestion that certain therapies can improve outcome, in those patients with adverse prognostic markers. In the Hemato-Oncologie voor Volwassenen Nederland 65 (HOVON-65) trial, ${ }^{7}$ bortezomibbased therapy improved PFS (12 months versus 26.2 months) in those patients carrying $17 \mathrm{p}$ deletion in comparison to those treated with a thalidomide combination regimen. However, bortezomib was unable to completely overcome the adverse impact of this marker, as the OS rate in bortezomib-treated

Table 2 Definition and survival of combined FISH and ISS risk groups

\begin{tabular}{lll}
\hline Group & $\begin{array}{l}\text { Combined FISH } \\
\text { and ISS risk group }\end{array}$ & $\begin{array}{l}\text { Median OS } \\
\text { (months) }\end{array}$ \\
\hline $\begin{array}{l}\text { ISS I and no lesions } \\
\text { ISS I and I lesion }\end{array}$ & Favorable risk & 67.8 \\
ISS II and no lesion & Intermediate risk & 41.3 \\
ISS I and > I lesion & & \\
ISS II and I lesion & & \\
ISS III and no lesion & & 19.4 \\
ISS III and I lesion & Ultra-high risk & \\
ISS II and > I lesion & & \\
ISS III and > I lesion & &
\end{tabular}

Note: Data from Boyd et al. ${ }^{6}$

Abbreviations: FISH, fluorescence in situ hybridization; ISS, International Staging System; OS, overall survival. 
patients with $17 \mathrm{p}$ deletion remained inferior to the non-17p deleted bortezomib-treated population. The Intergroupe Francophone du Myelome (IFM) group demonstrated a similar pattern of results with patients treated with bortezomib-dexamethasone (VD) versus vincristinedoxorubicin-dexamethasone (VAD) chemotherapy. ${ }^{7,8}$ In contrast to this, however, the Gruppo Italiano Malattie e Matologiche dell'Adulto (GIMEMA) Group study showed that bortezomib-thalidomide-dexamethasone (VTD) was able to overcome the adverse impact of $t(4 ; 14)$ with significantly improved PFS rates (61\% versus $20 \%$ ) compared to those treated with thalidomide-dexamethasone alone. ${ }^{9}$ Recently a meta-analysis has confirmed these findings by comparing bortezomib-based against non-bortezomib-based regimens. Those patients with high-risk cytogenetics treated with the former had better complete remission (CR) and non-CR rates compared to the latter ( $41 \%$ versus $22 \%$ ), which translated into prolonged PFS (35.9 months versus 28.6 months). ${ }^{10}$

Importantly, it has also been noted that some patients with cytogenetic lesions can have an impaired outcome to certain therapies. For instance, in the MRC Myeloma IX study, patients with poor prognostic cytogenetics had shorter PFS and OS when treated with thalidomide maintenance. ${ }^{11}$

It is therefore important that as we aim to optimize therapy for myeloma patients and choose appropriate therapies for individual patients, both disease-related and patient-related factors are taken into account. Although the following sections are split into TE and NTE sections, the disease-related factors discussed above apply equally to both groups.

\section{TE induction therapy}

In general, the main goal of induction in TE patients is to induce a very good partial response (VGPR) or greater either pre- or post-transplant, as this can have a significant impact on patient survival. ${ }^{12,13}$ The IFM 2005-01 and the UK Myeloma IX study highlighted this, where patients who achieved VGPR or greater following induction demonstrated prolonged median PFS in contrast to those who only achieved this after ASCT. ${ }^{14-16}$ Furthermore, in certain patient groups, not only achieving a CR but also maintaining this response can have major implications on outcome. This was particularly seen in the Total Therapy 2 study, where a higher proportion of those patients with adverse cytogenetics who achieved $\mathrm{CR}$ remained relapse-free for 7 years compared to those who did not $(45 \%$ versus $20 \%) .{ }^{17}$ However, it should be noted that pursuing the goal of $\mathrm{CR}$ and minimal residual disease negativity should not be to the detriment of long-term quality of life.

\section{Combination regimens}

The choice of drugs and combinations for induction chemotherapy pre-transplant has changed significantly over the last few decades, with a move from the previous gold standard regimen combining VAD to using the so-called "novel agents" proteasome inhibitors and IMiDs with chemotherapy and steroids. ${ }^{18}$ Furthermore, the number of drugs used in each combination has been studied extensively, with a greater emphasis placed on using three-drug rather than two-drug combinations (Table 3). ${ }^{15,19-21}$

\section{Thalidomide-based combination regimens}

The IMiDs thalidomide and lenalidomide are able to directly induce myeloma cell apoptosis and modulate the bone marrow microenvironment adversely to reduce cytokines important for myeloma cell growth and survival. Recent publications have demonstrated that many of these direct effects are via inhibition of an important E3 ubiquitin ligase with resulting downstream effects via IRF4. 22,23

In 2005, Cavo et al first highlighted the efficacy of thalidomide-dexamethasone (TD) against myeloma in a retrospective case-matched comparison against VAD. The response rate was significantly higher in patients treated with TD compared to VAD (76\% versus $52 \%)$ with $10 \%$ of the former achieving CR compared to $8 \%{ }^{19}$ This was further supported by a Phase III trial conducted later comparing TD with dexamethasone alone, with significantly higher overall response rates (ORR) in the former (63\% versus $46 \%)$ as well as prolonged PFS (14.9 months versus 6.5 months). ${ }^{18}$ As a result, TD became a commonly used induction regimen for patients prior to transplant.

Further Phase III studies have explored the combination of TD with a cytotoxic drug. One such study showed that the combination of Adriamycin ${ }^{\circledR}$ with TD demonstrated higher VGPR rates compared to VAD (37\% versus $18 \%$ ), which translated into prolonged median event-free survival (34 months versus 22 months). ${ }^{21}$ In addition, the MRC Myeloma IX trial found patients treated with cyclophosphamide-TD had significantly higher ORR compared to its combination with VAD $(82.5 \%$ versus $71.2 \%$ ). Furthermore, patients who achieved CR had a greater PFS compared to those who achieved less than this (39 months versus 32 months). ${ }^{15}$

Therefore, results suggest a three-drug regimen including thalidomide results in good ORR, PFS, and OS. The main disadvantage associated with the use of thalidomide, 
Table 3 Summary of Phase II/III trials in transplant-eligible patients

\begin{tabular}{|c|c|c|c|c|}
\hline Author, year & Drug combinations & $\begin{array}{l}\text { ORR ( }>\text { PR) after } \\
\text { induction (\%) }\end{array}$ & $\begin{array}{l}\text { Median PFS } \\
\text { months }\end{array}$ & $\begin{array}{l}\text { Median OS } \\
\text { months }\end{array}$ \\
\hline \multirow[t]{2}{*}{ Cavo et al, $2005^{19}$} & TD vs & 76 & NA & NA \\
\hline & VAD & 52 & NA & NA \\
\hline \multirow[t]{2}{*}{ Rajkumar et al, $2006^{20}$} & TD vs & 61 & 6.5 & NA \\
\hline & dexamethasone & 41 & 14.9 & NA \\
\hline \multirow[t]{2}{*}{ Lokhorst et al, $2010^{21}$} & TAD vs & 71 & 34 & 73 \\
\hline & VAD & 57 & 22 & 60 \\
\hline \multirow[t]{2}{*}{ Morgan et al, $2012^{15}$} & CTD vs & 82.5 & 27 & NR (range 0-74) \\
\hline & CVAD & 71.2 & 25 & 63 (range I-73) \\
\hline \multirow[t]{4}{*}{ Jagannath et al, $2005^{26}$} & VD & 88 & NA & Est $12,(87 \%)^{*}$ \\
\hline & (patients received bortezomib & NA & NA & NA \\
\hline & alone for the first two cycles then & & & \\
\hline & VD for cycles 3-6) & & & \\
\hline \multirow[t]{2}{*}{ Harousseau et al, $2010^{27}$} & Bortezomib-dexamethasone vs & 78.5 & 36 & NR \\
\hline & VAD & 62.8 & 29.7 & NR \\
\hline Reeder et al, $2009^{28}$ & CVD & 88 & NA & NA \\
\hline \multirow[t]{2}{*}{ Sonneveld et al, $2012^{29}$} & PAD vs & 78 & 35 & $60,(61 \%)^{*}$ \\
\hline & VAD & 54 & 28 & $60,(55 \%)^{*}$ \\
\hline \multirow{2}{*}{ Cavo et al, $2010^{30}$} & VTD vs & 93 & $36,(68 \%)^{*}$ & $36,(86 \%)^{*}$ \\
\hline & TD & 79 & $36,(56 \%)^{*}$ & $36,(84 \%)^{*}$ \\
\hline Sonneveld et al, $2013^{34}$ & Carfilzomib $+\mathrm{Td}$ & 96 & (74\% of 70 patients)* & (7\% of 70 patients) ${ }^{*}$ \\
\hline \multirow[t]{2}{*}{ Rajkumar et al, $2010^{35}$} & Rd vs & 70 & 25.3 & $(96 \%)^{*}$ \\
\hline & $\mathrm{RD}$ & 81 & 19.1 & $(87 \%)^{*}$ \\
\hline \multirow[t]{2}{*}{ Pawlyn et al, $2013^{36}$} & CRD vs & 83 & NA & NA \\
\hline & CRDa & 73 & NA & NA \\
\hline Richardson et al, $2010^{37}$ & VRD & 100 & Est $18,(75 \%)^{*}$ & Est I8, $(97 \%)^{*}$ \\
\hline Roussel et al, $2010^{38}$ & VRD & 97 & NA & NA \\
\hline \multirow[t]{3}{*}{ Kumar et al, $2012^{39}$} & CVD vs & 75 & 12, (93\%)* & $12,(100 \%) *$ \\
\hline & CVRD vs & 88 & $(86 \%)^{*}$ & $(92 \%)^{*}$ \\
\hline & VRD & 85 & $(83 \%)^{*}$ & $(100 \%)^{*}$ \\
\hline Jakubowiak et al, $2012^{40}$ & Carfilzomib + Rd & 97 & Est $24,(92 \%)^{*}$ & NA \\
\hline Korde et al, $2013^{41}$ & Carfilzomib + RD-R & 96 & 10, (follow-up 83.3\%)* & NA \\
\hline \multirow[t]{2}{*}{ Moreau et al, $20 \mathrm{II}^{31}$} & VTD vs & 88 & $26 * *$ & NA \\
\hline & VD & 81 & $30 * *$ & NA \\
\hline
\end{tabular}

Notes: *Some of the trials had fixed follow-up at 36 months, hence why some of the data is shown as percentage. **High variability in treatment administered post ASCT in both groups.

Abbreviations: ASCT, autologous stem cell transplant; CRD, cyclophosphamide-lenalidomide-dexamethasone; CRDa, attenuated dose of cyclophosphamide-lenalidomidedexamethasone; CTD, cyclophosphamide-thalidomide-dexamethasone; CVAD, cyclophosphamide-bortezomib-doxorubicin-dexamethasone; CVD, cyclophosphamidebortezomib-dexamethasone; CVRD, cyclophosphamide-bortezomib-lenalidomide-dexamethasone; Est, estimated; NA, not assessed; NR, not reached; ORR, overall response rate; OS, overall survival; PAD, bortezomib-doxorubicin-dexamethasone; PFS, progression-free survival; PR, partial response; Rd, lenalidomide-low-dose dexamethasone; RD, lenalidomide-dexamethasone; RD-R, lenalidomide-dexamethasone followed by lenalidomide maintenance; TAD, thalidomide-doxorubicin-dexamethasone; Td, thalidomide-low-dose dexamethasone; TD, thalidomide-dexamethasone; VAD, vincristine-doxorubicin-dexamethasone; VD, bortezomib-dexamethasone; vs, versus; VRD, bortezomib-lenalidomide-dexamethasone; VTD, bortezomib-thalidomide-dexamethasone.

however, is its adverse effects (eg, neuropathy, somnolence, and venous thromboembolisms), which have led to high discontinuation rates. $^{24}$

\section{Bortezomib-based combination regimens}

In vitro studies have demonstrated that proteasome inhibition has pleiotropic effects on the myeloma cell and bone marrow microenvironment. Importantly, the attenuation of signaling pathways important for myeloma cell growth results in myeloma cell apoptosis and effects on the osteoblast-osteoclast axis, resulting in a potential normalization of the adverse bone marrow microenvironment. ${ }^{25}$
As well as inducing high level cytotoxicity alone, bortezomib demonstrated significant synergistic activity when combined with dexamethasone in vitro, making this a popular regimen for the relapsed setting. However, in 2005, Jagannath et al administered this combination as induction therapy to previously untreated patients and produced high $\mathrm{CR}$ and non-CR rates, suggesting this regimen could be as effective upfront. ${ }^{26}$ The effectiveness of VD was later confirmed in a randomized setting, where this combination was compared to VAD. ${ }^{27}$ Post-induction, both the CR/non-CR rate $(14.8 \%$ versus $6.4 \%)$ and VGPR rate $(37.7 \%$ versus $15.1 \%$ ) were significantly higher in the bortezomib group 
compared to the VAD group. These results did not appear to be subgroup dependent as responses were seen regardless of the disease stage or adverse cytogenetics. Furthermore, the ORR to subsequent transplant was higher in the bortezomib group compared to VAD $(80.3 \%$ versus $77.1 \%)$, proving the effectiveness of this drug on both post-induction and post-transplant response rates. ${ }^{27}$

In order to try and enhance the effectiveness of VD, several trials have added a cytotoxic drug, such as doxorubicin or cyclophosphamide. The latter, in particular, demonstrated high response rates with $71 \%$ patients achieving VGPR following four cycles of therapy. Furthermore, all patients underwent a successful stem cell harvest, and post-transplant maintained profound responses to this treatment with $\mathrm{CR} /$ non-CR found in $70 \%$ and VGPR in $74 \% .{ }^{28}$ Importantly, the Hemato-Oncologie voor Volwassenen Nederland (HOVON) group have conducted a Phase III trial randomizing patients to either receive bortezomib-doxorubicin-dexamethasone or VAD followed by ASCT. Overall, higher VGPR rates were seen in those patients in the bortezomib-doxorubicin-dexamethasone group (75\% versus $61 \%$ ) with excellent PFS rates (35 months versus 28 months) compared to the VAD-treated group. Additionally, the bortezomib-doxorubicin-dexamethasone regimen was well tolerated with $82 \%$ patients receiving full-dose bortezomib. ${ }^{29}$

There has been a keen interest in improving these high response rates by using multiple agents within a triplet regimen. In 2010, Cavo et al conducted one of the first trials combining bortezomib with TD (VTD) as induction prior to transplantation, comparing this to TD. ${ }^{30}$ The response rates following induction were higher in the VTD group compared to $\mathrm{TD}$, with $\mathrm{CR} /$ non-CR achieved in $31 \%$ versus $11 \%$, respectively, which then translated into prolonged estimated 3-year PFS (68\% versus 56\%). There were unfortunately a higher number of grade III/IV adverse events reported in the VTD group, particularly peripheral neuropathy; however, this did resolve or improve in 18 of 23 patients affected. ${ }^{30}$

In order to try and address the adverse event picture, attenuated doses of bortezomib and thalidomide have been explored. The IFM study compared the combination of VD at full dose against VTD at reduced dose. Despite these dose changes, the reduced-dose VTD group still demonstrated higher rates of CR and VGPR (49\% versus 36\%) with a reduced incidence of peripheral neuropathy (14\% versus $34 \%$ ), making this an effective triplet regimen to consider for patients prior to $\mathrm{ASCT}^{31}$

Alternative therapeutic options have also been explored, with recent increasing interest in carfilzomib - a proteasome inhibitor that is structurally distinct from bortezomib. In contrast to bortezomib, the incidence of reported peripheral neuropathy is low and rarely graded above two. ${ }^{32}$ A number of studies are exploring three drug combinations including carfilzomib in the upfront setting although formal reports are awaited..$^{33,34}$

\section{Lenalidomide-based combination regimens}

Lenalidomide was first used as front-line therapy in an open label, randomized controlled trial, comparing its combination with either low-dose or high-dose dexamethasone. It was found to be highly effective with response rates of $68 \%$ with lenalidomide-low-dose dexamethasone and $79 \%$ with lenalidomide-high-dose dexamethasone. Unfortunately, the higher doses of lenalidomide-dexamethasone were associated with greater toxicity and early mortality, particularly in patients aged more than 65 years, thus favoring the combination of lenalidomide-low-dose dexamethasone. ${ }^{35}$

Again, in order to try and improve response rates and PFS, a number of groups have developed three-drug combination regimens based on the lenalidomide backbone. The MRC Myeloma XI trial has combined cyclophosphamidelenalidomide-dexamethasone. All patients tolerated this combination well, receiving a median of five cycles pretransplant and achieving high ORR of $83 \%$, suggesting that this combination could be an effective induction therapy in the future. ${ }^{36}$

Given the potential benefit of combining novel agents, Richardson et al have taken the approach of combining two novel agents in a small Phase I/II study combining bortezomiblenalidomide-dexamethasone (VRD) in newly diagnosed patients. The response rates achieved in the Phase II population were high with $74 \%$ achieving VGPR or greater; with median follow-up of 21 months, the estimated 18-month PFS for this combination with or without ASCT was $75 \% .{ }^{37}$ Furthermore, in another study, the quality of response was shown to improve when VRD was given both at induction and consolidation, with VGPR rates increasing from $54 \%$ to $89 \%{ }^{38}$ Importantly, the adverse event profile was favorable with only gradeI/II peripheral neuropathy reported in both studies, and few thromboembolic events. Given these promising initial results, further studies in larger patient groups are warranted.

Following on from this, Kumar et al explored the possibility of improving response rates and survival further by using a four-drug regimen, comparing VRD against cyclophosphamide-bortezomib-dexamethasone and cyclophosphamide-VRD. ${ }^{39}$ Interestingly, this Phase II trial demonstrated similar response rates between all three drug combinations, showing no significant advantage of using a four-drug regimen. Furthermore, cyclophosphamide-VRD 
was associated with higher rates of hematological toxicity despite using a lower dose of lenalidomide.

More recently, the newer proteasome inhibitor carfilzomib has also been investigated in combination with lenalidomide and dexamethasone in newly diagnosed patients. After a median of twelve cycles, $62 \%$ of patients achieved non-CR and $42 \%$ stringent $\mathrm{CR}$ with few adverse events reported. Additionally, the estimated 24-month PFS rate after 13 months follow-up was $92 \%$. Jakubowiak et a ${ }^{40}$ and Korde et $\mathrm{al}^{41}$ have presented similar results using the same three-drug combination, where $63 \%$ of patients achieved stringent $\mathrm{CR} / \mathrm{CR} /$ non-CR and many achieved a minimal disease state on flow cytometry, making this a viable regimen to consider in newly diagnosed patients. ${ }^{40,41}$

One precaution to note with lenalidomide is the potential for this drug to reduce stem cell mobilization prior to transplant. Although studies have been contradictory, it is currently recommended that harvesting is done within the first four cycles of therapy with the use of cyclophosphamideGCSF to mobilize stem cells. ${ }^{42}$

In conclusion, a large number of randomized Phase III studies demonstrate the importance of the use of induction chemotherapy pre-transplant to reduce tumor burden and to treat the underlying end organ damage. ${ }^{14}$ Overall, it is recommended to use a three-drug combination with either thalidomide, lenalidomide, or bortezomib, a traditional chemotherapeutic agent, and steroid, or a three-drug combination with two novel agents. Studies have demonstrated that the level of response pre-autograft has prognostic significance, confirming one of the major aims of this part of the treatment scheme is to achieve the best response possible. $^{13}$

\section{Transplantation and consolidation}

A number of large randomized studies suggest the gold standard treatment approach for TE patients is to administer induction therapy followed by ASCT, then to consider consolidation and continuous therapy. ${ }^{43}$ The aim of this sequential approach is to reduce tumor bulk, aiming for $\mathrm{CR}$, and, through various drug combinations, minimize the risk of relapse from residual myeloma cells. ${ }^{44}$

Questions have recently been raised, however, as to whether ASCT should be used at all in young, fit patients, given the high response rates with novel agents alone. ${ }^{45,46}$ As a result, there are two large ongoing Phase III studies investigating upfront ASCT against chemotherapy. The first (NCT01208766) is being run by the European Myeloma Network, comparing bortezomib-melphalan-prednisone (VMP) induction against high-dose melphalan and ASCT, followed by VRD consolidation then lenalidomide maintenance. The second is the IFM and Dana-Farber Cancer Institute 10-106 trial randomizing patients to receive VRD or ASCT. ${ }^{47}$

Consolidation treatment has recently been used to improve responses following ASCT, as achieving CR has been associated with prolonged PFS and OS following transplantation. ${ }^{13}$ The upgrade in response rates has been particularly noted in two major studies: the Nordic Myeloma Group and the IFM 2005-02 group. ${ }^{48,49}$ The former randomized patients to receive either no consolidation or bortezomib for 3 months following ASCT. A significant difference in improvement of response was noted, with the proportion of $\mathrm{CR} /$ non-CR rising from $23 \%$ to $54 \%$ in the bortezomib arm. ${ }^{48}$ The IFM 2005-02 study randomized patients to either receive lenalidomide consolidation followed by maintenance treatment with lenalidomide or maintenance with placebo. It was again noted that consolidation treatment allowed patients to upgrade their response, with 29 patients improving from VGPR to $\mathrm{CR} .{ }^{49}$

As well as using single agents, the combination of multiple agents as consolidation has also yielded higher response rates, with up to $60 \%$ of VTD-treated patients in the GIMEMA Group trial achieving molecular remission compared to TD-treated patients. ${ }^{9}$ However, despite these promising results, it is yet to be established whether consolidation therapy actually confers a significant survival benefit, especially as it is often followed by a maintenance block, meaning the individual effects of each component of therapy are difficult to assess. ${ }^{3}$

\section{NTE combination regimens}

The majority of myeloma patients are aged above 65 years; however, they are often underrepresented in clinical trial reports due to their comorbidities and frailty. ${ }^{50}$ In addition, this patient group is often associated with poorer survival rates due to a combination of more aggressive myeloma biology (ie, advanced International Staging System stage and poor prognostic markers) and poor tolerance of therapyrelated toxicities due to a progressive decrease in physiological reserve. ${ }^{51}$

Although the induction regimens described previously can be applied to NTE candidates, a number of less intensive regimens have been adopted to try and improve tolerance in this frailer group of patients. For many years, melphalanprednisone (MP) has been the gold standard for NTE patients. However, with the introduction of IMiDs and proteasome inhibitors, results have shown that combining MP with 
Table 4 Phase III trials in non-transplant-eligible patients

\begin{tabular}{|c|c|c|c|c|c|c|}
\hline Author, year & $\begin{array}{l}\text { Regimen (number } \\
\text { of patients) }\end{array}$ & CR (\%) & $\begin{array}{l}>\text { VGPR } \\
\text { (\%) }\end{array}$ & $\begin{array}{l}\text { ORR } \\
(\%)\end{array}$ & $\begin{array}{l}\text { Median PFS } \\
\text { (months) }\end{array}$ & $\begin{array}{l}\text { Median OS } \\
\text { (months) }\end{array}$ \\
\hline \multirow[t]{2}{*}{ Palumbo et al, $2008^{52}$} & MPT (167) & 15.6 & 29.3 & 68.9 & 21.8 & 45 \\
\hline & MP (I64) & 3.7 & II & 47.6 & 14.5 & 47.6 \\
\hline \multirow[t]{4}{*}{ Facon et al, $2007^{53}$} & MPT (I25) & 13 & 47 & 76 & 27.5 & 51.6 \\
\hline & MP (196) & 2 & 7 & 35 & 17.8 & 33.2 \\
\hline & Reduced-intensity & 18 & 43 & 65 & 19.4 & 38.3 \\
\hline & ASCT (126) & & & & & \\
\hline \multirow[t]{2}{*}{ Waage et al, $2010^{54}$} & MPT (I82) & 13 & 23 & 57 & 15 & 29 \\
\hline & MP (I75) & 4 & 7 & 40 & 14 & 32 \\
\hline \multirow[t]{4}{*}{ Wijermans et al, $2010^{55}$} & MPT (165) & Unavailable as & 27 & 66 & 13 & 40 \\
\hline & $M P(168)$ & immunofixation & 10 & 45 & 9 & 31 \\
\hline & & not performed & & & & \\
\hline & & on all patients & & & & \\
\hline \multirow[t]{2}{*}{ Hulin et al, 200956} & MPT (II7) & 7 & 21 & 62 & 24.1 & 44 \\
\hline & $M P(I \mid 5)$ & 1 & 7 & 31 & 18.5 & 29.1 \\
\hline \multirow[t]{2}{*}{ Morgan et al, $201 I^{58}$} & CTDa (426) & 13.1 & 16.9 & 63.8 & 13 & 33.2 \\
\hline & MP (423) & 2.4 & 1.7 & 32.6 & 12.4 & 30.6 \\
\hline San Miguel et al, & VMP (344) & 33 & 71 & NA & 21.7 & $N R$ \\
\hline $2008 / 2013^{59,60}$ & MP (338) & 4 & 35 & NA & 15.2 & NR \\
\hline \multirow[t]{2}{*}{ Palumbo et al, $2008^{62}$} & VMPT (193) & 31 & 55 & NA & $24,86.8 \% *$ & $36,89.5 \% *$ \\
\hline & VMP (200) & 16 & 42 & NA & $24,78.1 \% *$ & $36,88.7 \% *$ \\
\hline \multirow[t]{2}{*}{ Mateos et al, $2012^{63}$} & VMP (80) & 18 & NA & 78 & NA & NA \\
\hline & VTP (87) & 23 & NA & 78 & NA & NA \\
\hline \multirow[t]{3}{*}{ Larocca et al, $2013^{64}$} & $\operatorname{VP}(5 \mathrm{I})$ & NA & NA & 67 & 14 & $12,80 \% *$ \\
\hline & $\operatorname{VCP}(5 \mathrm{I})$ & NA & NA & 63 & 16 & $12,82 \% *$ \\
\hline & VMP (50) & NA & NA & 80 & 16 & $12,80 \% *$ \\
\hline \multirow[t]{2}{*}{ Rajkumar et al, $2010^{35}$} & $\operatorname{Rd}(222)$ & 4 & 26 & 70 & 25.3 & $12,96 \% *$ \\
\hline & $\mathrm{RD}(223)$ & 5 & 33 & 81 & 19.1 & $12,87 \% *$ \\
\hline Palumbo et al, $2007^{65}$ & MPR (54) & 47.6 & NA & 81 & $12,92.3 \% *$ & $12,100 \% *$ \\
\hline \multirow[t]{3}{*}{ Palumbo et al, $2012^{66}$} & MP (I54) & 3.2 & 9.1 & 50 & 13 & NR \\
\hline & MPR (I53) & 3.3 & 29.4 & 68 & 14 & NR \\
\hline & MPR-R (I52) & 9.9 & 23.0 & 77 & 31 & 45.2 \\
\hline
\end{tabular}

Note: *The percentage values represent the proportion of patients who were alive within each treatment group after a fixed follow-up period.

Abbreviations: ASCT, autologous stem cell transplantation; CR, complete remission; CTDa, attenuated dose of cyclophosphamide-thalidomide-dexamethasone; MP, melphalan-prednisone; MPR, melphalan-prednisone-lenalidomide; MPR-R, melphalan-prednisone-lenalidomide followed by lenalidomide maintenance; MPT, melphalan-prednisone-thalidomide; NA, not assessed; NR, not reached; ORR, overall response rate; OS, overall survival; PFS, progression-free survival; Rd, lenalidomidelow-dose dexamethasone; RD, lenalidomide-dexamethasone; VCP, bortezomib-cyclophosphamide-prednisone; VGPR, very good partial response; VMP, bortezomibmelphalan-prednisone; VMPT, bortezomib-melphalan-prednisone-thalidomide; VP, bortezomib-prednisone; VTP, bortezomib-thalidomide-prednisone.

thalidomide (MPT) or bortezomib (ie, VMP) can produce higher response rates (Table 4).

\section{Thalidomide}

There have been multiple randomized controlled trials comparing MP against MPT, with results showing higher response rates and longer PFS with MPT. ${ }^{52-56}$ While some MPT studies have shown an improvement in OS, other trials have shown no significant survival benefit. This is intriguing and most likely due to the toxicity experienced by patients limiting dose and duration of treatment. A recent meta-analysis, however, did demonstrate a prolonged PFS and a trend towards improved OS associated with thalidomide-based regimens. ${ }^{57}$

As well as melphalan, thalidomide has also been assessed as part of an attenuated regimen in combination with cyclophosphamide and dexamethasone as part of the
MRC Myeloma IX trial. This combination was compared with MP, with significantly higher ORR associated with an attenuated dose of cyclophosphamide-TD (63.8\% versus $32.6 \%$, respectively); although survival outcomes were equivocal. ${ }^{58}$ In conclusion, these studies clearly show MPT/ cyclophosphamide-TD are superior to MP; however, the toxicity profile of thalidomide is unique and requires careful monitoring, with the aim of ensuring patients can remain on therapy.

\section{Bortezomib}

The successful combination of bortezomib with chemotherapy in the NTE setting was first demonstrated by the Phase III Velcade $^{\circledR}$ As Initial Standard Therapy in Multiple Myeloma: Assessment With Melphalan and Prednisone (VISTA) trial, which compared VMP against MP. ${ }^{59,60}$ VMP was associated 
with significantly higher $\mathrm{CR}$ and $\mathrm{PR}$ rates $(71 \%$ versus $35 \%$, respectively), which translated into prolonged OS (56.4 months versus 43.1 months), although at the expense of a higher rate of adverse events (46\% versus $36 \%$ ). ${ }^{60}$

It has long been suspected that bortezomib-induced peripheral neuropathy is related to dose intensity and by either reducing the dose from $1.3 \mathrm{mg} / \mathrm{m}^{2}$ to $1.0 \mathrm{mg} / \mathrm{m}^{2}$ or increasing dosing interval from twice weekly to once weekly, the incidence of this toxicity can be reduced.$^{61}$ Palumbo et al applied this concept in patients aged above 65 years, comparing VMP against VMP-thalidomide, where in both groups, patients were further subdivided to receive either twice weekly or once weekly bortezomib infusions. ${ }^{62}$ Overall, the VMPthalidomide group was superior to VMP with higher CR rates (31\% versus 16\%) and prolonged 2-year PFS (83.9\% versus $75.7 \%$ ). Importantly, the weekly infusion of bortezomib significantly decreased the incidence of grade III/IV peripheral neuropathy in both groups without influencing outcome. ${ }^{62}$ This experience was also supported in the Spanish multicenter study by Mateos et al, comparing VMP against bortezomib-thalidomide-prednisone, where weekly bortezomib was shown to be extremely well tolerated. ${ }^{63}$

These studies further highlight the need to consider adverse event management and quality of life when treating patients with myeloma. Importantly, ensuring a regimen is tolerable results in patients remaining on therapy for the full treatment course and thus attaining the maximum benefit from that line of therapy. Taking this concept further, Larocca et al recently assessed treatment compliance and response in frail patients using reduced-intensity subcutaneous bortezomib-prednisone either alone or in combination with cyclophosphamide or melphalan (ie, VMP). The patients received a median of nine cycles and elicited good ORR (greater than PR) with 67\% in bortezomib-prednisone, $63 \%$ in bortezomib-cyclophosphamide-prednisone, and $80 \%$ in VMP. This translated into prolonged PFS of 14, 16, and 16 months, respectively, with the highest discontinuation rates in the VMP group (26\%). The similarities in response rates and PFS suggest that it may be possible to treat elderly patients with a reduced-intensity melphalan-free regimen without compromising their disease control. ${ }^{64}$

\section{Lenalidomide}

As mentioned previously, the initial study of lenalidomide in the upfront setting demonstrated that elderly patients tolerated low-dose dexamethasone better than high-dose dexamethasone with improved survival benefit (2-year OS 97\% versus $75 \%) .{ }^{35}$ Subsequently, this IMiD has also been investigated in combination with melphalan and prednisone (MPR) as part of a Phase I/II study in 54 patients with newly diagnosed multiple myeloma. A large proportion of those patients who received the maximum tolerated dose (melphalan $0.18 \mathrm{mg} /$ $\mathrm{kg}$ /day and lenalidomide $10 \mathrm{mg}$ /day) demonstrated high response rates, with an ORR $81 \%$ observed in this subgroup. ${ }^{65}$ Furthermore, with a median follow-up of 14.6 months, the 1 -year event-free survival was $92.3 \%$ with 1 -year OS of $100 \%$ in all patients. As expected, the most common toxicities reported were grade III/IV neutropenia, thrombocytopenia, and anemia, with the drug being discontinued in six patients and reduced in three. ${ }^{65}$

This study led to the initiation of a large randomized trial comparing MP alone against MPR, followed by maintenance with either lenalidomide (MPR-R) or placebo. ${ }^{66}$ Response rates were superior with both MPR-R and MPR compared to MP (77\% versus $68 \%$ versus $50 \%$, respectively) with prolonged median PFS (31 months versus 14 months versus 13 months). The most reported adverse events were again hematological, with grade IV neutropenia more commonly found with MPR-R compared to MP (35\% versus $8 \%$ ). These results highlight that in an elderly population monitoring for adverse events and acting promptly with GCSF support, dose reduction or dose delay is clearly important.

\section{Clinical assessment: comorbidities and frailty index}

The results from the Larocca et al study described above highlight that more treatment is not always best, and that prior to commencing treatment in NTE patients their level of fitness for treatment needs to be clinically assessed. A number of formal and informal methods can be used; for instance, this can be based on the presence of comorbidities (defined as more than two medically diagnosed diseases) or the patients' frailty index. The latter is defined as the presence of more than three core elements of frailty: weakness, poor endurance, weight loss, low physical activity, and slow gait speed. ${ }^{67}$ Studies of cancer patients have found that those with a high number of comorbidities and frailty index have poorer outcomes. ${ }^{68}$

As a result, there has now been a general recommendation that treatment is adapted to the individual patient based on the presence of risk factors, using the "go-go, moderate-go, and slow-go" system (Table 5 and Figure 2). ${ }^{68}$ This system is based on expert opinion and now allows the opportunity to perform clinical studies in the frail elderly population where an improvement in response rate, PFS, and OS is desperately needed. 
Table 5 Dose adjustment levels

\begin{tabular}{|c|c|c|c|}
\hline Agent & Dose level 0 & Dose level I & Dose level 2 \\
\hline Dexamethasone & $\begin{array}{l}40 \mathrm{mg} / \text { day on days I, } 8,15 \text {, } \\
\text { and } 22 \text { every } 4 \text { weeks }\end{array}$ & $\begin{array}{l}20 \mathrm{mg} / \text { day on days I, } 8, \mathrm{I} \text {, and } \\
22 \text { every } 4 \text { weeks }\end{array}$ & $\begin{array}{l}10 \mathrm{mg} / \text { day on days I, } 8,15 \text {, } \\
\text { and } 22 \text { every } 4 \text { weeks }\end{array}$ \\
\hline Melphalan & $\begin{array}{l}0.25 \mathrm{mg} / \mathrm{kg} \text { on days } \mathrm{I}-4 \text { every } \\
4-6 \text { weeks }\end{array}$ & $\begin{array}{l}0.18 \mathrm{mg} / \mathrm{kg} \text { on days } \mathrm{I}-4 \text { every } \\
4-6 \text { weeks }\end{array}$ & $\begin{array}{l}0.13 \mathrm{mg} / \mathrm{kg} \text { on days } \mathrm{I}-4 \text { every } \\
4-6 \text { weeks }\end{array}$ \\
\hline Thalidomide & $100 \mathrm{mg} /$ day & $50 \mathrm{mg} /$ day & $50 \mathrm{mg}$ every other day \\
\hline Lenalidomide & $\begin{array}{l}25 \mathrm{mg} / \text { day on days I-2I every } \\
4 \text { weeks }\end{array}$ & $\begin{array}{l}\text { I5 mg/day on days I-2I } \\
\text { every } 4 \text { weeks }\end{array}$ & $\begin{array}{l}10 \mathrm{mg} / \text { day on days I-2I every } \\
4 \text { weeks }\end{array}$ \\
\hline Bortezomib & $\begin{array}{l}\text { I. } 3 \mathrm{mg} / \mathrm{m}^{2} \text { twice weekly on days } \\
\mathrm{I}, 4,8 \text {, and I I every } 3 \text { weeks }\end{array}$ & $\begin{array}{l}\mathrm{I} .3 \mathrm{mg} / \mathrm{m}^{2} \text { once weekly on days } \\
\mathrm{I}, 8, \mathrm{I} 5 \text {, and } 22 \text { every } 5 \text { weeks }\end{array}$ & $\begin{array}{l}1.0 \mathrm{mg} / \mathrm{m}^{2} \text { once weekly on days } \\
\mathrm{I}, 8, \mathrm{I} 5 \text {, and } 22 \text { every } 5 \text { weeks }\end{array}$ \\
\hline
\end{tabular}

Note: Data from Palumbo et al. ${ }^{68}$

Overall, there are multiple treatment options for NTE patients as two- or three-drug combinations including thalidomide, bortezomib, or lenalidomide have exhibited high levels of activity. Ideally, patients should receive at least nine cycles of therapy and achieve a stable maximum response, although the optimal length of treatment is yet to be determined. ${ }^{68}$ In order to achieve this, however, a patientadapted approach needs to be taken in order to maximize treatment benefit without impairing quality of life.

\section{Long-term disease control in TE and NTE}

As described in the earlier sections, the introduction of the IMiDs and proteasome inhibitors has led to higher response rates and prolonged survival..$^{69}$ This has been mainly attributed to patients achieving a greater depth of response, with both VGPR and CR being associated with prolonged PFS and OS. ${ }^{70,71}$ As a result, there has been increasing focus on the

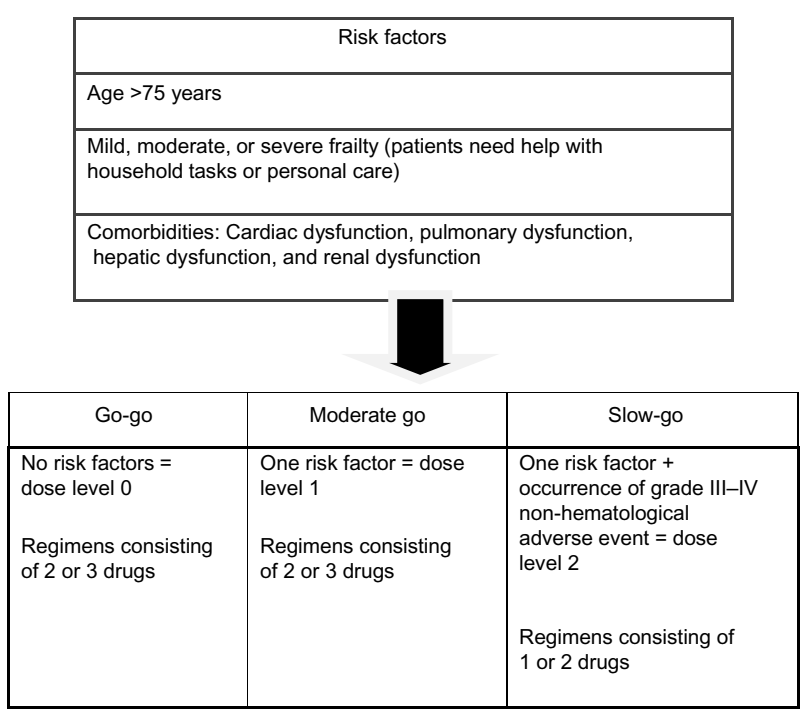

Figure 2 Risk factors and adapted treatment approaches for elderly patients. Note: Data from Palumbo et al..$^{68}$ use of continuous ongoing therapy rather than a set number of treatment cycles to sustain disease control with the aim of improving PFS and OS further. Clearly, during this disease phase when patients have a low tumor burden, are well, and are participating in normal every day activities, it is important that the continuous therapy does not impair quality of life or result in side effects.

\section{Thalidomide}

Thalidomide has been explored as continuous therapy in both TE and NTE patients. In the TE group, there have been five large Phase III studies, of which three have demonstrated an OS benefit when thalidomide was used as maintenance therapy. ${ }^{21,72-74}$ In the elderly population, several trials have compared MPT against MP, followed by continuous thalidomide maintenance treatment. Some of these have tried to tailor the dose, eg, in the HOVON-49 study, a lower dose of thalidomide was used in order to reduce the incidence of toxicities associated with this drug. ${ }^{55}$ However, despite this, the MPT arm was associated with a higher number of grade II or higher adverse events, which was one of the main reasons for patients to go off study. Furthermore, despite showing a PFS advantage, patients aged greater than 75 years did not have a significant $\mathrm{OS}$ benefit. ${ }^{55} \mathrm{In}$ all of the studies looking at thalidomide as ongoing therapy, the side effect of peripheral neuropathy was the major issue resulting in the median time on treatment being between 6-12 months. Therefore, the general consensus by the International Myeloma Working Group is to use a minimal effective dose of thalidomide (ie, 50-100 mg daily) for a limited time period. ${ }^{75}$

\section{Bortezomib}

Bortezomib has been considered an attractive alternative for continuous therapy to thalidomide since, although it is delivered either intravenously or subcutaneously, it has limited toxicities and therefore may be better tolerated. In 
the HOVON-65 study, Sonneveld et al randomized patients to receive either thalidomide $50 \mathrm{mg}$ daily or bortezomib $1.3 \mathrm{mg} / \mathrm{m}^{2}$ once every 2 weeks for 2 years following high-dose ASCT. After a median follow-up of 41 months, the median PFS and OS was superior in those receiving bortezomib compared to thalidomide. Furthermore, fewer patients discontinued this drug, with only $11 \%$ patients stopping due to toxicity compared to $30 \%$ of patients taking thalidomide. ${ }^{29}$

In elderly patients, bortezomib has been combined with other agents as maintenance therapy. Mateos et al compared bortezomib-thalidomide against bortezomib-prednisone following induction with either VMP or bortezomibthalidomide-prednisone. The bortezomib-thalidomide group was associated with significantly higher CR rates (46\% versus 39\%) as well as prolonged PFS (39 months versus 32 months). In both groups, however, bortezomib was given twice weekly intravenously for up to 3 years and, as a result, a number of patients did develop peripheral neuropathy (9\% versus $3 \%){ }^{63}$

A number of approaches have been attempted to try and reduce the side effects and improve quality of life of patients receiving continuous bortezomib therapy. Recently, a systematic review of all trials using bortezomib-based regimens found that using either a reduced dose or frequency of administration significantly reduced the incidence of neuropathy, while still retaining efficacy. ${ }^{76}$ The UPFRONT study is a good example of this, in which bortezomib was administered once weekly for 25 weeks as maintenance following a bortezomibbased induction regimen. Patients tolerated the drug well, with few discontinuations reported, while also showing an improvement in their response rates. ${ }^{77}$

Subcutaneous bortezomib has also been explored as an alternative method to reduce toxicity and improve compliance. Moreau et al compared subcutaneous against intravenous bortezomib in relapsed patients and demonstrated a decreased incidence of side effects with similar response rates, time-to-progression, and OS. ${ }^{78}$ Hence, the subcutaneous route has now been widely adopted as the delivery method of choice for newly diagnosed patients being considered for continuous therapy.

\section{Lenalidomide}

Lenalidomide has shown strong anti-myeloma activity, particularly as induction and relapse therapy in both TE and NTE patients. Furthermore, it has a limited toxicity profile and can be administered orally, making it an ideal option for continuous therapy. ${ }^{79}$ There have been two large Phase III studies exploring the use of lenalidomide post-transplant: the Cancer and Leukemia Group B 100104 study, which randomized patients to receive either lenalidomide or placebo after ASCT until disease progression, and the IFM 05-02 study, which assigned all patients to receive consolidation with lenalidomide then be randomized to either continue this as maintenance or have placebo. In both studies, those patients in the lenalidomide arm showed significant PFS benefit, while the Cancer and Leukemia Group B study alone demonstrated an OS advantage. There was a higher incidence of grade III or higher hematological toxicities and thromboembolic events reported in the lenalidomide arm, although discontinuation rates remained low. ${ }^{49,79}$

Due to its tolerability, particularly the lack of peripheral neuropathy, lenalidomide is a favorable option in NTE elderly patients. In a recent large Phase III study, patients older than 65 years were randomized to receive MPR-R or alternatively MPR or MP without maintenance. After a median follow-up of 31 months, the MPR-R group had a significantly prolonged PFS compared to the other groups, as well as superior response rates. ${ }^{66}$

Continuous therapy with lenalidomide is also effective in the relapsed setting. In two parallel trials, Multiple Myeloma-009 and Multiple Myeloma-010, patients were randomized to receive either lenalidomide or placebo in combination with dexamethasone. ${ }^{80,81}$ The majority of patients had been exposed to more than two previous therapies, including thalidomide and ASCT. The treatment group who received lenalidomide until disease progression had a significantly prolonged time-to-progression compared to placebo (11.1 months versus 4.7 months) with higher response rates $(60.2 \%$ versus $24 \%){ }^{81}$

As with all treatments, the long-term consequences of prolonged treatment need to be considered. Lenalidomide has been previously reported to increase the risk of secondary primary malignancies, particularly hematological malignancies such as acute myeloid leukemia and myelodysplastic syndromes. ${ }^{82}$ In both of the Phase III transplant studies described above, an increased incidence of secondary primary malignancies was found in the lenalidomide group compared to placebo ( $8 \%$ versus $4 \%$ in IFM $0502 ; 9 \%$ versus $3 \%$ in Cancer and Leukemia Group B 100104). ${ }^{80,81}$

Recently, Palumbo et al performed a meta-analysis comparing the rate of secondary primary malignancies in patients who were exposed to lenalidomide or not. The cumulative incidence of solid and hematological secondary primary malignancies was similar, regardless of whether the patient received lenalidomide or not. However, exposure to lenalidomide in combination with oral melphalan did 
significantly increase the risk of hematological secondary primary malignancies, suggesting that melphalan should be avoided and alternative combinations, including either cyclophosphamide or dexamethasone, should be considered in newly diagnosed patients. ${ }^{83}$ Overall, however, it was concluded that the survival benefit associated with lenalidomide still outweighed the potential risk of secondary primary malignancies, in keeping with other reviews of this subject. $^{83-85}$

\section{Pomalidomide}

Pomalidomide is one of the newest IMiDs that has shown greater activity than thalidomide and lenalidomide in vitro. Recently, results have been released from the Multiple Myeloma-003 trial which compared pomalidomide plus low-dose dexamethasone until disease progression against high-dose dexamethasone alone. ${ }^{86}$ Patients had to be diagnosed with relapsed or refractory multiple myeloma and had failed at least two previous treatments including both bortezomib and lenalidomide to be eligible for the study. After median follow-up of 10 months, patients receiving continuous pomalidomide with dexamethasone had a prolonged PFS (4 months versus 1.9 months) and OS (12.7 months versus 8.1 months). In addition, a high ORR was observed irrespective of previous treatment. Furthermore, it was well tolerated with toxicities being primarily hematological and as a result, it is recommended that all patients receive prophylactic antibiotics in the first three cycles, as well as thromboprophylaxis. ${ }^{87}$

\section{Zoledronic acid}

As well as treating the underlying disease, bisphosphonates have been shown to be important in maintaining good bone health and improving the quality of life of myeloma patients. Importantly, recent studies exploring the role of bisphosphonates demonstrated that continuous treatment results in a decrease in skeletal-related events as well as an improvement in PFS and OS. The MRC Myeloma IX study examined the effect of zoledronic acid against clodronic acid in patients with myeloma. In both TE and NTE pathways, patients receiving zoledronic acid showed a survival benefit with median OS extended to 50 months compared to 44.5 months in the group receiving clodronic acid. This data supported increasing preclinical evidence of anti-myeloma effects exerted by zoledronic acid, and supports early and continuous use of this agent in myeloma patients. ${ }^{88}$

Overall, in both TE and NTE patients, continuous therapy seems to be an effective method of prolonging remission and survival. However, ensuring the regimen is tolerable and does not impair quality of life is imperative during these prolonged periods of remission. Moving forward, further studies are warranted to examine the potential of continuous therapy to accidentally select for resistant/aggressive clones and subsequent relapses that result in poorer responses and shorter PFS than would be expected.

\section{Conclusion}

The management of multiple myeloma remains complex, although the advent of therapies with new mechanisms of action has allowed clinicians to develop multiple treatment strategies, including treatment blocks at induction, consolidation, maintenance, and relapse. Furthermore, with the increasing use of cytogenetics, and better management of comorbidities and treatment side effects, it is becoming possible to optimize therapy on an individual patient basis, allowing for better response rates, longer treatment duration, and improved patient compliance. The latter is an important factor to consider as myeloma is increasingly becoming a chronic disease, meaning that more focus is being placed on the use of ongoing therapy to maintain long-term disease control. Myeloma is an evolving disease and ultimately disease control can be lost, resulting in patients being refractory to the available treatment strategies. Increasingly, we are learning lessons concerning long-term disease control from colleagues treating other chronic diseases such as tuberculosis, chronic bronchitis, diabetes mellitus, and human immunodeficiency virus. It is hoped that by adapting our continuous treatment strategies and tailoring our approaches to the individual patient, we may be able to minimize this resistance, decrease the side effect profile, and improve patient outcome.

\section{Disclosure}

Priya Sriskandarajah declares no conflict of interest in this work. Faith E Davies has had a consulting/advisory relationship with Acetylon, Millennium, Janssen and Celgene; and has also received honoraria from Janssen and Celgene.

\section{References}

1. International Myeloma Working Group. Criteria for the classification of monoclonal gammopathies, multiple myeloma and related disorders: a report of the International Myeloma Working Group. Br J Haematol. 2003;121(5):749-757.

2. Bird J, Owen R, d'Sa S, et al. Guidelines on the Diagnosis and Management of Multiple Myeloma. London: British Committee for Standards in Haematology; 2010. Available from: http://www. bcshguidelines.com/documents/MYELOMA_Mngmt_GUIDELINE_ REVISION_Sept_2010.pdf. Accessed June 9, 2014. 
3. Cavo M, Rajkumar SV, Palumbo A, et al. International Myeloma Working Group consensus approach to the treatment of multiple myeloma patients who are candidates for autologous stem cell transplantation. Blood. 2011;117(23):6063-6073.

4. Fonseca R, Bergsagel PL, Drach J, et al. International Myeloma Working Group molecular classification of multiple myeloma: spotlight review. Leukemia. 2009;23(12):2210-2221.

5. Chang WJ, Dispenzieri A, Chim CS, et al. IMWG consensus on risk stratification in multiple myeloma. Leukemia. 2014;28(2):269-277.

6. Boyd KD, Ross FM, Chiecchio L, et al. A novel prognostic model in myeloma based on co-segregating adverse FISH lesions and the ISS: analysis of patients treated in the MRC Myeloma IX trial. Leukemia. 2012;26(2):349-355.

7. Avet-Loiseau H, Leleu X, Roussel M, et al. Bortezomib plus dexamethasone induction improves outcome of patients with $t(4 ; 14)$ myeloma but not outcome of patients with del(17p). J Clin Oncol. 2010;28(30):4630-4634.

8. Neben K, Lokhorst HM, Jauch A, et al. Administration of bortezomib before and after autologous stem cell transplantation improves outcome in multiple myeloma patients with deletion 17p. Blood. 2012;119(4): 940-948.

9. Cavo M, Pantani L, Petrucci MT, et al. Bortezomib-thalidomidedexamethasone is superior to thalidomide-dexamethasone as consolidation therapy after autologous hematopoietic stem cell transplantation in patients with newly diagnosed multiple myeloma. Blood. 2012;120(1):9-19.

10. Sonneveld P, Goldschmidt H, Rosinol L, et al. Bortezomib-based versus nonbortezomib-based induction treatment before autologous stem-cell transplantation in patients with previously untreated multiple myeloma: a meta-analysis of Phase III randomized, controlled trials. J Clin Oncol. 2013;31(26):3279-3287.

11. Morgan GJ, Davies FE, Gregory WM, et al. Long-term follow-up of MRC Myeloma IX trial: survival outcomes with bisphosphonate and thalidomide treatment. Clin Cancer Res. 2013;19(21):6030-6038.

12. Harousseau JL, Attal M, Avet-Loiseau H. The role of complete response in multiple myeloma. Blood. 2009;114(15):3139-3146.

13. Durie BG. Role of new treatment approaches in defining treatment goals in multiple myeloma - the ultimate goal is extended survival. Cancer Treat Rev. 2010;36(Suppl 2):S18-S23.

14. Moreau P, Attal M, Pegourie B, et al. Achievement of VGPR to induction therapy is an important prognostic factor for longer PFS in the IFM 2005-01 trial. Blood. 2011;117(11):3041-3044.

15. Morgan GJ, Davies FE, Gregory WM, et al. Cyclophosphamide, thalidomide and dexamethasone as induction therapy for newly diagnosed multiple myeloma patients destined for autologous stemcell transplantation: MRC Myeloma IX randomized trial results. Haematologica. 2012;97(3):442-450.

16. Rawstron AC, Child JA, de Tute RM, et al. Minimal residual disease assessed by multiparameter flow cytometry in multiple myeloma: impact on outcome in the Medical Research Council Myeloma IX Study. J Clin Oncol. 2013;31(20):2540-2547.

17. Barlogie B, Pineda-Roman M, van Rhee F, et al. Thalidomide arm of Total Therapy 2 improves complete remission duration and survival in myeloma patients with metaphase cytogenetic abnormalities. Blood. 2008;112(8):3115-3121.

18. Jasielec JK, Jakubowiak AJ. Current approaches to the initial treatment of symptomatic multiple myeloma. Int J Hematol Oncol. 2013;2(1).

19. Cavo M, Zamagni E, Tosi P, et al. Superiority of thalidomide and dexamethasone over vincristine-doxorubicin-dexamethasone (VAD) as primary therapy in preparation for autologous transplantation for multiple myeloma. Blood. 2005;106(1):35-39.

20. Rajkumar SV, Blood E, Vesole D, Fonseca R, Greipp PR. Phase III clinical trial of thalidomide plus dexamethasone compared with dexamethasone alone in newly diagnosed multiple myeloma: a clinical trial coordinated by the Eastern Cooperative Oncology Group. J Clin Oncol. 2006;24(3):431-436.
21. Lokhorst HM, van der Holt B, Zweegmen S, et al. A randomised Phase III study on the effect of thalidomide combined with adriamycin, dexamethasone, and high-dose melphalan, followed by thalidomide maintenance in patients with multiple myeloma. Blood. 2010;115(6): 1113-1120.

22. Kronke J, Udeshi ND, Narla A, et al. Lenalidomide causes selective degradation of IKZF1 and IKZF3 in multiple myeloma cells. Science. 2014;343(6168):301-305.

23. Lu G, Middleton RE, Sun H, et al. The myeloma drug lenalidomide promotes the cereblon-dependent destruction of Ikaros proteins. Science. 2014;343(6168):305-309

24. Barlogie B, Tricot G, Anaissie E, et al. Thalidomide and hematopoietic-cell transplantation for multiple myeloma. $N$ Engl J Med. 2006;354(10):1021-1030.

25. Hideshima T, Richardson P, Chauhan D, et al. The proteasome inhibitor PS-341 inhibits growth, induces apoptosis, and overcomes drug resistance in human multiple myeloma cells. Cancer Res. 2001;61(7):3071-3076.

26. Jagannath S, Durie B, Wolf J, et al. Bortezomib therapy alone and in combination with dexamethasone for previously untreated symptomatic multiple myeloma. Br J Haematol. 2005;129(6):776-783.

27. Harousseau JL, Attal M, Avet-Louiseau H, et al. Bortezomib plus dexamethasone is superior to vincristine plus doxorubicin plus dexamethasone as induction treatment prior to autologous stem-cell transplantation in newly diagnosed multiple myeloma: results of the IFM 2005-01 Phase III trial. J Clin Oncol. 2010;28(30):4621-4629.

28. Reeder CB, Reece DE, Kukreti V, et al. Cyclophosphamide, bortezomib, and dexamethasone induction for newly diagnosed multiple myeloma: high response rates in a Phase II clinical trial. Leukemia. 2009;23(7):1337-1341.

29. Sonneveld P, Schmidt-Wolf IG, van der Holt B, et al. Bortezomib induction and maintenance treatment in patients with newly diagnosed multiple myeloma: results of the randomized Phase III HOVON-65/ GMMG-HD4 trial. J Clin Oncol. 2012;30(24):2946-2955.

30. Cavo M, Tacchetti P, Patriarca F, et al. Bortezomib with thalidomide plus dexamethasone compared with thalidomide plus dexamethasone as induction therapy before, and consolidation therapy after, double autologous stem-cell transplantation in newly diagnosed multiple myeloma: a randomized Phase III study. Lancet. 2010;376(9758): 2075-2085.

31. Moreau P, Avet-Loiseau H, Facon T, et al. Bortezomib plus dexamethasone versus reduced-dose bortezomib, thalidomide plus dexamethasone as induction treatment before autologous stem cell transplantation in newly diagnosed multiple myeloma. Blood. 2011;118(22):5752-5758.

32. Redic K. Carfilzomib: a novel agent for multiple myeloma. J Pharm Pharmacol. 2013;65(8):1095-1106.

33. Bringhen S, Cerrato C, Petrucci MT, et al. A Phase II study with carfilzomib, cyclophosphamide, and dexamethasone (CCd) for newly diagnosed multiple myeloma [abstract]. Blood. 2013;122(21): abstract 685 .

34. Sonneveld P, Asselberg-Hacker E, Zweegman S, et al. Dose escalation Phase II trial of carfilzomib combined with thalidomide and low-dose dexamethasone in newly diagnosed, transplant eligible patients with multiple myeloma. A trial of the European Myeloma Network [abstract]. Blood. 2013;122(21):abstract 688.

35. Rajkumar SV, Jacobus S, Callander NS, et al. Lenalidomide plus highdose dexamethasone versus lenalidomide plus low-dose dexamethasone as initial therapy for newly diagnosed multiple myeloma: an open-label randomised controlled trial. Lancet Oncol. 2010;11(1):29-37.

36. Pawlyn C, Brioli A, Gregory W, et al. Lenalidomide combined with cyclophosphamide and dexamethasone is effective and well tolerated treatment for newly diagnosed myeloma patients of all ages [abstract]. Blood. 2013;122(21):abstract 540.

37. Richardson PG, Weller E, Lonial S, et al. Lenalidomide, bortezomib, and dexamethasone combination therapy in patients with newly diagnosed multiple myeloma. Blood. 2010;116(5):679-686. 
38. Roussel M, Avet-Loiseau H, Moreau P, et al. Frontline therapy with bortezomib, lenalidomide and dexamethasone (VRD) followed by autologous stem cell transplantation, VRD consolidation and lenalidomide maintenance in newly diagnosed multiple myeloma patients: primary results of the IFM 2008 Phase II study [abstract]. Blood. 2010;116(21):abstract 624.

39. Kumar S, Flinn I, Richardson PG, et al. Randomized, multicenter, Phase II study (EVOLUTION) of combinations of bortezomib, dexamethasone, cyclophosphamide, and lenalidomide in previously untreated multiple myeloma. Blood. 2012;119(19):4375-4382.

40. Jakubowiak AJ, Dytfield D, Griffith KA, et al. A Phase I/II study of carfilzomib in combination with lenalidomide and low-dose dexamethasone as a frontline treatment for multiple myeloma. Blood. 2012;120(9):1801-1809.

41. Korde N, Zingone A, Kwok ML, et al. Phase II clinical and correlative study of carfilzomib, lenalidomide, and dexamethasone followed by lenalidomide extended dosing (CRD-R) induces high rates of MRD negativity in newly diagnosed multiple myeloma (MM) patients [abstract]. Blood. 2013;122(21):abstract 538.

42. Kumar S, Giralt S, Stadtmauer EA, et al. Mobilization in myeloma revisited: IMWG consensus perspectives on stem collection following initial therapy with thalidomide-, lenalidomide-, or bortezomib-containing regimens. Blood. 2009;114(9): 1729-1735.

43. Palumbo A. Transplantation for myeloma: work in progress. J Clin Oncol. 2012;30(24):2935-2936.

44. Morgan GJ. Transplants for the elderly in myeloma. Blood. 2013;122(8):1332-1334.

45. Moreau P, Rajkumar SV. Should all eligible patients with multiple myeloma receive autologous stem cell transplant as part of initial treatment? Leuk Res. 2012;36(6):677-681.

46. Blade J, Rosinol L, Sureda A, et al. High-dose therapy intensification compared with continued standard chemotherapy in multiple myeloma patients responding to the initial chemotherapy: long-term results from a prospective randomized trial from the Spanish Cooperative Group PETHEMA. Blood. 2005;106(12):3755-3759.

47. Richardson PG. Randomized trial of lenalidomide, bortezomib, dexamethsone vs high-dose treatment with SCT in MM patients up to age 65 (DFCI 10-106). Available from: http://clinicaltrials.gov/ct2/show/ NCT01208662. NLM identifier: NCT01208662. Accessed March 1, 2014.

48. Mellqvist UH, Gimsing P, Hjertner O, et al. Bortezomib consolidation after autologous stem cell transplantation in multiple myeloma: a Nordic Myeloma Study Group randomized Phase III trial. Blood. 2013;121(23):4647-4654.

49. Attal M, Lauwers-Cances V, Marit G, et al. Lenalidomide maintenance after stem-cell transplantation for multiple myeloma. $N \mathrm{Engl} \mathrm{J} \mathrm{Med}$. 2012;366(19):1782-1791.

50. Wedding U, Rohrig B, Klippstein A, Pientka L, Hoffken K. Age, severe comorbidity, and functional impairment independently contribute to poor survival in cancer patients. J Cancer Res Clin Oncol. 2007;133(12): 945-950.

51. Ludwig H, Durie BG, Bolejack V, et al. Myeloma in patients younger than age of 50 years presents with more favorable features and shows better survival: an analysis of 10,549 patients from the International Myeloma Working Group. Blood. 2008;111(8):4039-4047.

52. Palumbo A, Bringhen S, Liberati AM, et al. Oral melphalan, prednisone, and thalidomide in elderly patients with multiple myeloma: updated results of a randomized controlled trial. Blood. 2008;112(8): 3107-3114.

53. Facon T, Mary JY, Hulin C, et al. Melphalan and prednisone plus thalidomide versus melphalan and prednisone alone or reducedintensity autologous stem cell transplantation in elderly patients with multiple myeloma (IFM 99-06): a randomized trial. Lancet. 2007;370(9594):1209-1218.

54. Waage A, Gimsing P, Fayers P, et al. Melphalan and prednisone plus thalidomide or placebo in elderly patients with multiple myeloma. Blood. 2010;116(9):1405-1412.
55. Wijermans P, Schaafsma M, Termorshuizen F, et al. Phase III study of the value of thalidomide added to melphalan plus prednisone in elderly patients with newly diagnosed multiple myeloma: the HOVON 49 Study. J Clin Oncol. 2010;28(19):3160-3166.

56. Hulin C, Facon T, Rodon P, et al. Efficacy of melphalan and prednisone plus thalidomide in patients older than 75 years with newly diagnosed multiple myeloma: IFM 01/01 trial. J Clin Oncol. 2009;27(22): 3664-3670.

57. Kapoor P, Rajkumar SV, Dispenzieri A, et al. Melphalan and prednisone versus melphalan, prednisone, and thalidomide for elderly and/or transplant ineligible patients with multiple myeloma: a meta-analysis. Leukemia. 2011;25(4):689-696.

58. Morgan GJ, Davies FE, Gregory WM, et al. Cyclophosphamide, thalidomide, and dexamethasone (CTD) as initial therapy for patients with multiple myeloma unsuitable for autologous transplantation. Blood. 2011;118(5):1231-1238.

59. San Miguel JF, Schlag R, Khuageva NK, et al. Bortezomib plus melphalan and prednisone for initial treatment of multiple myeloma. N Engl J Med. 2008;359(9):906-917.

60. San Miguel JF, Schlag R, Khuageva NK, et al. Persistent overall survival benefit and no increased risk of second malignancies with bortezomib-melphalan-prednisone versus melphalan-prednisone in patients with previously untreated multiple myeloma. J Clin Oncol. 2013;31(4):448-455.

61. Mohty B, El-Cheikh J, Yakoub-Agha I, Moreau P, Harousseau JL, Mohty M. Peripheral neuropathy and new treatments for multiple myeloma: background and practical recommendations. Haematologica. 2010;95(2):311-319.

62. Palumbo A, Bringhen S, Rossi D, et al. A prospective, randomised, Phase III study of bortezomib, melphalan, prednisone, and thalidomide (VMPT) versus bortezomib, melphalan, and prednisone (VMP) in elderly newly diagnosed myeloma patients [abstract]. Blood. 2008;112(11):abstract 652 .

63. Mateos MV, Oriol A, Martinez-Lopez J, et al. Maintenance therapy with bortezomib plus thalidomide or bortezomib plus prednisone in elderly multiple myeloma patients included in the GEM2005MAS65 trial. Blood. 2012;120(13):2581-2588.

64. Larocca A, Cavallo F, Magarotto V, et al. Reduced dose-intensity subcutaneous bortezomib plus prednisone (VP) or plus cyclophosfamide (VCP) or plus melphalan (VMP) for newly diagnosed multiple myeloma patients over 75 years of age [abstract]. Blood. 2013;122(21):abstract 539.

65. Palumbo A, Falco P, Corradini P, et al. Melphalan, prednisone, and lenalidomide treatment for newly diagnosed myeloma: report from the GIMEMA - Italian Multiple Myeloma Network. J Clin Oncol. 2007;25(28):4459-4465.

66. Palumbo A, Hajek R, Delforge M, et al. Continuous lenalidomide treatment for newly diagnosed multiple myeloma. $N$ Engl J Med. 2012;366(19):1759-1769.

67. Engelhardt M, Terpos E, Kleber M, et al. European Myeloma Network recommendations on the evaluation and treatment of newly diagnosed patients with multiple myeloma. Haematologica. 2014;99(2):232-242.

68. Palumbo A, Bringher S, Ludwig H, et al. Personalized therapy in multiple myeloma according to patient age and vulnerability: a report of the European Myeloma Network (EMN). Blood. 2011;118(17):4519-4529.

69. Kumar SK, Rajkumar SV, Dispenzieri A, et al. Improved survival in multiple myeloma and the impact of novel therapies. Blood. 2008;111(5):2516-2520.

70. Alvares CL, Davies FE, Horton C, et al. Long-term outcomes of previously untreated myeloma patients: responses to induction chemotherapy and high-dose melphalan incorporated within a risk stratification model can help to direct the use of novel therapies. Br J Haematol. 2005;129(5):607-614.

71. Harousseau JL, Avet-Loiseau H, Attal M, et al. Achievement of at least very good partial response is a simple and robust prognostic factor in patients with multiple myeloma treated with high-dose therapy: long-term analysis of the IFM 99-02 and 99-04 trials. J Clin Oncol. 2009;27(34):5720-5726. 
72. Attal M, Harousseau JL, Leyvraz S, et al. Maintenance therapy with thalidomide improves survival in patients with multiple myeloma. Blood. 2006;108(10):3289-3294.

73. Spencer A, Prince HM, Roberts AW, et al. Consolidation therapy with low-dose thalidomide and prednisolone prolongs the survival of multiple myeloma patients undergoing a single autologous stem-cell transplantation procedure. J Clin Oncol. 2009;27(11):1788-1793.

74. Morgan GJ, Gregory WM, Davies FE, et al. The role of maintenance thalidomide therapy in multiple myeloma: MRC Myeloma IX results and meta-analysis. Blood. 2012;119(1):7-15.

75. Ludwig H, Durie BG, McCarthy P, et al. IMWG consensus on maintenance therapy in multiple myeloma. Blood. 2012;119(13):3003-3015.

76. Sopena M, Clavero EM, Villa P, Martinez-Lopez J. Efficacy and safety of reduced-intensity induction therapy with a bortezomib-based regimen in elderly patients with multiple myeloma. Ther Adv Hematol. 2012;3(3):147-154.

77. Niesvizky R, Flinn IW, Rifkin RM, et al. Phase IIIb UPFRONT study: safety and efficacy of weekly bortezomib maintenance therapy after bortezomib-based induction regimens in elderly, newly diagnosed multiple myeloma patients [abstract]. Blood. 2010;116(2):abstract 619.

78. Moreau P, Pylypenko H, Grosicki S, et al. Subcutaneous versus intravenous administration of bortezomib in patients with relapsed multiple myeloma: a randomized, Phase III, non-inferiority study. Lancet Oncol. 2011;12(5):431-440.

79. McCarthy PL, Owzar K, Hofmeister CC, et al. Lenalidomide after stem-cell transplantation for multiple myeloma. $N$ Engl J Med. 2012;366(19):1770-1781.

80. Weber DM, Chen C, Niesvizky R, et al. Lenalidomide plus dexamethasone for relapsed multiple myeloma in North America. N Engl J Med. 2007;357(21):2133-2142.
81. Dimopoulos M, Spencer A, Attal M, et al. Lenalidomide plus dexamethasone for relapsed or refractory multiple myeloma. $N$ Engl J Med. 2007;357(21):2123-2132.

82. Moreau P. The future of therapy for relapsed/refractory multiple myeloma: emerging agents and novel treatment strategies. Semin Hematol. 2012;49(Supp1 1):S33-S46.

83. Palumbo A, Bringhen S, Kumar SK, et al. Second primary malignancies with lenalidomide therapy for newly diagnosed myeloma: a meta-analysis of individual patient data. Lancet Oncol. 2014;15(3): 333-342.

84. Dimopoulos MA, Richardson PG, Brandenburg N, et al. A review of second primary malignancy in patients with relapsed or refractory multiple myeloma treated with lenalidomide. Blood. 2012;119(12):2764-2767.

85. Landgren O, Thomas A, Mailankody S. Myeloma and second primary cancers. N Engl J Med. 2011;365(23):2241-2242.

86. Miquel JS, Weisel K, Moreau P, et al. Pomalidomide plus low-dose dexamethasone versus high-dose dexamethasone alone for patients with relapsed and refractory multiple myeloma (MM-003): a randomized, open-label, Phase III trial. Lancet Oncol. 2013;14(11): 1055-1066.

87. Dimopoulos MA, Leleu X, Palumbo A, et al. Expert panel consensus statement on the optimal use of pomalidomide in relapsed and refractory multiple myeloma. Leukemia. Epub February 5, 2014.

88. Morgan GJ, Davies FE, Gregory WM, et al. First-line treatment with zoledronic acid as compared with clodronic acid in multiple myeloma (MRC Myeloma IX): a randomized controlled trial. Lancet. 2010;376(9757):1989-1999.
Blood and Lymphatic Cancer: Targets and Therapy

\section{Publish your work in this journal}

Blood and Lymphatic Cancer: Targets and Therapy is an international, peer-reviewed, open access journal focusing on blood and lymphatic cancer research, identification of therapeutic targets and the optimal use of preventative and integrated treatment interventions to achieve improved outcomes, enhanced survival and quality of life for the

\section{Dovepress}

cancer patient. The manuscript management system is completely online and includes a very quick and fair peer-review system. Visit http://www.dovepress.com/testimonials.php to read real quotes from published authors. 